AU1

\title{
Combining a Cloud-Resolving Model with Satellite for Cloud Process Model Simulation Validation
}

\author{
Renato G. Negri ANd Luiz A. T. Machado \\ Divisão de Satélites e Sistemas Ambientais, Centro de Previsão de Tempo e Estudos Climáticos, \\ Instituto Nacional de Pesquisas Espaciais, Cachoeira Paulista, São Paulo, Brazil \\ STEPHEN ENGLISH \\ European Centre for Medium-Range Weather Forecasts, Reading, United Kingdom \\ MARY FORSYTHE \\ Met Office, Exeter, United Kingdom
}

(Manuscript received 1 June 2012, in final form 29 September 2013)

\begin{abstract}
Advances in computer power have made it possible to increase the spatial resolution of regional numerical models to a scale encompassing larger convective elements of less than $5 \mathrm{~km}$ in size. One goal of high resolution is to begin to resolve convective processes and therefore, it is necessary to evaluate the realism of convective clouds resolved explicitly at this resolution. This paper presents a methodology based on satellite comparisons to examine the simulation of continental tropical convection over Africa, in a high-resolution integration of the Met Office Unified Model (UK UM), developed under the Cascade project. The spatial resolution of these simulations is $1.5 \mathrm{~km}$, the temporal resolution is $15 \mathrm{~min}$, and the convection is resolved explicitly. The Spinning Enhanced Visible and Infrared Imager (SEVIRI) radiometer measurements were simulated by the Radiative Transfer for the Television and Infrared Observation Satellite (TIROS) Operational Vertical Sounder (RTTOV) model and then a comparison between the simulations and real SEVIRI measurements was performed. The analysis using the presented methodology shows that the UK UM can represent tropical convection dynamics realistically. However, an error has been found in the high-level humidity distribution, which is characterized by strong humidity gradients. A key point of this paper is to present a methodology for establishing the credibility of a convection-permitting model by direct comparison with satellite data.
\end{abstract}

ABSTRACT

\section{Introduction}

Many operational forecast centers are taking advantage of the computer power now available to produce convection-permitting NWP forecasts over limited domains. One motivation for this action is to increase the forecast quality for extreme events, such as severe convection and rain. Many studies have offered evidence that high-resolution models can increase the forecast skill (Romero et al. 2001; Speer and Leslie 2002; Done et al. 2004). Regional models with horizontal grid

Corresponding author address: Renato Galante Negri, DSA, CPTEC, INPE, Rod Presidente Dutra, Km 40, Cachoeira Paulista, São Paulo 12630-000, Brazil.

E-mail: renato.galante@cptec.inpe.br spacing from 12 up to $4 \mathrm{~km}$ have been implemented in many centers, and it is likely that in the coming years, models with $1-\mathrm{km}$ horizontal grid spacing will become increasingly common (Lean et al. 2008).

At a horizontal resolution of $50 \mathrm{~km}$, some improvements can be made in the simulation of the diurnal cycle (Ploshay and Lau 2010) in comparison with lowerresolution models. By increasing the horizontal resolution to $10 \mathrm{~km}$, one can begin to resolve cloud systems and the interactions between them. Thus, precipitation and its variability can be simulated with increasing realism (Sato et al. 2009). This resolution has required the development of operational nonhydrostatic models (Davies et al. 2005). The nonhydrostatic Met Office Unified Model (UK UM) was used operationally for many years with a resolution of $12 \mathrm{~km}$. For a full description

DOI: 10.1175/JAMC-D-12-0178.1 
of the UK UM, see Lean et al. (2008). Lean et al. (2008) evaluated the UK UM skill in short-range forecasting of convective rainfall over the United Kingdom. They examined three different configurations of the UK UM with horizontal resolutions of 12,4 , and $1 \mathrm{~km}$, analyzing various cases of convection for the summers of 2003, 2004, and 2005. Their focus was on the rainfall characteristics of the convection, but they also derived convective cell statistics - counting the number and determining the horizontal size of the cells within each model configuration. They found that the 4-km UK UM configuration tends to produce a small number of large convective cells,

AU4 whereas the $1-\mathrm{km}$ version produces a larger number of smaller convective cells.

Barnaby et al. (2011) studied the diurnal cycle in simulations made by the UK UM as part of the Cascade project. They compared three horizontal resolutions $(40,12$, and $4 \mathrm{~km})$ in a limited area over the Indonesian archipelago, and they found a dry bias in the mean precipitation at $40 \mathrm{~km}$. At $12-\mathrm{km}$ resolution, the mean precipitation over the archipelago was improved, but there was still a wet bias over the continent and a dry bias over the ocean. Last, at $4 \mathrm{~km}$, when the convection was resolved explicitly, the model exhibited a systematic wet bias because the moisture was not conserved by the semi-Lagrangian advection scheme used.

Many other studies have also aimed to evaluate the convection scheme in forecast models at the mesoscale and synoptic scale, where the model convection is compared with real satellite measurements. Chaboureau et al. (2000) assessed the life cycle of a cloud system, simulated by a mesoscale model with an explicit cloud scheme, as part of the Fronts and Atlantic Storm Track Experiment (FASTEX). They compared the synthetic cloud fields (simulated by a radiative transfer model) with the measured infrared brightness temperatures from the Meteosat Visible and Infrared Imager (MVIRI) on board the Meteosat First Generation geostationary satellite. In their study, the simulations reproduced very well the key patterns of convection in the infrared images. A full description of FASTEX can be found in Joly et al. (1997). Chevallier and Kelly (2002) made several comparisons between the infrared window channel (band 10.5-12.5 $\mu \mathrm{m}$ ) of MVIRI and simulations using the Radiative Transfer for the Television and Infrared Observation Satellite (TIROS) Operational Vertical Sounder

AU5 (RTTOV) forward radiative transfer model using global model data from the European Centre for MediumRange Weather Forecasts. Ringer et al. (2003) developed a system capable of simulating satellite radiances by using atmospheric profiles from the forecast and climate versions of UK UM and, furthermore, they made comparisons with MVIRI. Slingo et al. (2004) assessed the diurnal cycle of convection in the Met Office Hadley Centre climate model [Hadley Centre Atmosphere Model, version 3 (HadAM3)] by using the methodology described by Ringer et al. (2003).

This study examines the simulation of convection over tropical Africa in a high-resolution $(1.5 \mathrm{~km})$ integration of the UK UM atmospheric version. These simulations were performed over tropical Africa during the period from 25 to 26 July 2006 as part of the Cascade project. The horizontal grid spacing of these simulations was $1.5 \mathrm{~km}$ and therefore, it was anticipated that some of the large convective elements would be resolved explicitly. The main objective of this work is to present a methodology to test the quality of a model at the scale of larger convective elements $(1.5 \mathrm{~km})$, focusing in particular on the representation and evolution of convective clouds. The characteristics of the model are evaluated by comparing simulated radiances to measured radiances from the Spinning Enhanced Visible and Infrared Imager (SEVIRI) on board Meteosat-9. A point-by-point comparison (e.g., Chaboureau et al. 2000 ) is not undertaken because the $1.5-\mathrm{km}$ UK UM runs were initialized from an interpolation of the $12-\mathrm{km}$ runs of the same model. In this case, the simulated radiances cannot be expected to correspond spatially with the SEVERI observations, but rather they exhibit similar statistics; thus, the attempt is to represent the climatologically correct behavior of the convection, not the actual convection at any particular moment. Therefore, the analysis here is performed statistically, and the goal is to verify whether the model can reproduce the same pattern of convection as that observed by satellite.

\section{Data and methodology}

This study aims to assess the representation of convection by the $1.5-\mathrm{km}$ configuration of UK UM over Africa as part of the Cascade project. We used the fast radiative transfer model RTTOV, version 9.3 (Eyre 1991; Saunders et al. 1999), to simulate the SEVIRI infrared radiances, which were then compared with observed SEVIRI imagery. These simulations were done separately to the UK UM code. A detailed statistical analysis of the observed and simulated radiances was undertaken by using an algorithm [Forecasting and Tracking the Evolution of Cloud Clusters (ForTraCC) (Vila et al. 2008)] to track the convective system life cycle. This algorithm allows the extraction of the convective life cycle characteristics (e.g., a cell's size, growth rate, and duration) from the simulations and real measurement datasets, which can be compared directly. Empirical orthogonal functions (EOFs) were also used to analyze the overall statistical behavior of the real and simulated radiances. 


\section{a. UK UM dataset-Cascade project}

Cascade is a Natural Environment Research Council (NERC)-funded consortium project to study organized convection in the tropical atmosphere by using model simulations to resolve large-domain cloud systems. Convection in the tropics is organized across a wide range of spatial and temporal scales, from a few kilometers and a few hours, through the mesoscale to the synoptic space-time scale. The diurnal cycle plays an important role in triggering and modulating these systems. Many of these scales are not well represented by weather and climate models, and the understanding of the interactions between these scales is poor. Simulations to study the interactions between these different scales require resolution that is sufficiently high to be able to resolve the individual cloud systems and a large-enough domain to capture the largest of these organizing scales (Natural Environment Research Council 2013).

The Cascade project uses a version of UK UM at horizontal resolutions of $1.5 \mathrm{~km}$ over typical domain sizes of $10000 \mathrm{~km} \times 3000 \mathrm{~km}$. The large domains allow the simulation of large-scale organization of convective systems. This makes it possible to determine explicitly the upscale transports of heat, moisture, and momentum and to investigate their contribution to the evolution of the synoptic- and planetary-scale systems. Only the area of $2^{\circ}-25^{\circ} \mathrm{N}, 20^{\circ} \mathrm{W}-16^{\circ} \mathrm{E}$ was evaluated in this study. This subset area of the full Cascade domain was chosen because this study is focused on tropical convection over land. This is the African Monsoon Multidisciplinary Analysis project region and therefore, additional measurements are available. It is also closer to the Meteosat- 8 subsatellite point, where images have less distortion. A sequence from 25 to 29 July 2006 was simulated by the UK UM configured with a horizontal grid resolution of $1.5 \mathrm{~km} \times 1.5 \mathrm{~km}, 71$ vertical levels, and the outputs were written every $15 \mathrm{~min}$. From this dataset, only two 18-h cases were chosen-26 and 27 July 2006-each one covering a time period from 1200 to 0600 UTC. The interval between the output times for the UK UM simulation is a quarter of an hour from 1200 to 2345 UTC, and hourly from 0000 to 0600 UTC. These extra $6 \mathrm{~h}$ of simulations were added to assess the overnight convection life cycle. UK UM, version 7, was used in the Cascade project. The UK UM uses a semi-implicit, semi-Lagrangian scheme on a rotated latitude-longitude grid (Davies et al. 2005), applying parameterizations to represent boundary layer turbulence (Locke et al. 2000) and mixed-phase microphysics (Wilson and Ballard 1999). A very detailed description of the UK UM can be found in Lean et al. (2008), and a specific description of the UK UM runs as part of the
TABLE 1. UK UM profiles used as input for the RTTOV simulations.

\begin{tabular}{ll}
\hline \hline \multicolumn{1}{c}{ 3D fields } & \multicolumn{1}{c}{ 2D fields } \\
\hline Pressure $(\mathrm{hPa})$ & Temperature at $1.5 \mathrm{~m}(\mathrm{~K})$ \\
Temperature $(\mathrm{K})$ & Specific humidity at $1.5 \mathrm{~m}(\mathrm{ppmv})$ \\
QCL $\left(\mathrm{kg} \mathrm{kg}^{-1}\right)$ & Surface temperature $(\mathrm{K})$ \\
QCF $\left(\mathrm{kg} \mathrm{kg}^{-1}\right)$ & Surface pressue $(\mathrm{hPa})$ \\
Cloud cover in each level (\%) & Land-sea mask \\
Ice cloud fraction $(\%)$ & \\
Water cloud fraction $(\%)$ & \\
\hline
\end{tabular}

Cascade project can be found in Pearson et al. (2010). The atmospheric profiles used as the input to the RTTOV model in this study are shown in Table 1 . The variables QCL and QCF in Table 1 are the specific amounts of ice and water, respectively, in the cloud for each level. The $1.5-\mathrm{km}$ model runs do not perform data assimilation, but they are initialized from an interpolation from the 12-km simulations of UK UM (Pearson et al. 2010). These $12-\mathrm{km}$ simulations were run in a limited-area mode forced with constant sea surface temperatures and initiated with analysis fields from the European Centre for Medium-Range Weather Forecasts.

\section{b. SEVIRI-RTTOV model simulations}

The SEVIRI sensor is a radiometer on board the Meteosat Second Generation (MSG) geostationary satellite series. It provides measurements in 12 spectral bands (channels): 3 channels in the visible spectrum (0.6 and $0.8 \mu \mathrm{m}$ and a broadband high-resolution visible), 1 in the near-infrared spectrum $(1.6 \mu \mathrm{m})$, and 8 in the infrared spectrum $(3.9,6.2,7.2,8.7,9.7,10.8,12$, and $13.4 \mu \mathrm{m})$. The spatial resolution of these channels is $3 \mathrm{~km} \times 3 \mathrm{~km}(1 \mathrm{~km} \times 1 \mathrm{~km}$ for the high-resolution visible) at nadir, and the MSG is located over the equator (Schmetz et al. 2002). All SEVIRI thermal channels from 3.9 to $13.4 \mu \mathrm{m}$, except the 9.7- $\mu \mathrm{m}$ ozone channel, were simulated by using RTTOV model, version 9.3. The ozone channel was not simulated because the ozone concentration profiles are not simulated by UK UM. SEVIRI radiances were simulated at the resolution of the Cascade dataset $(1.5 \mathrm{~km} \times 1.5 \mathrm{~km})$ for all UK UMselected outputs. For the radiative transfer calculation, it is assumed that only one kind of microphysics species exists in each grid volume and that it is distributed uniformly. When the ForTraCC analysis was performed, the spatial resolution of the simulated satellite imagery was decreased to $3 \mathrm{~km} \times 3 \mathrm{~km}$, by calculating a mean value of the $2 \times 2$ pixels, to reproduce the same situation as when using the real SEVIRI images. Only the $10.8-\mu \mathrm{m}$ channel was used because ForTraCC is based only in this wavelength. 
(a)
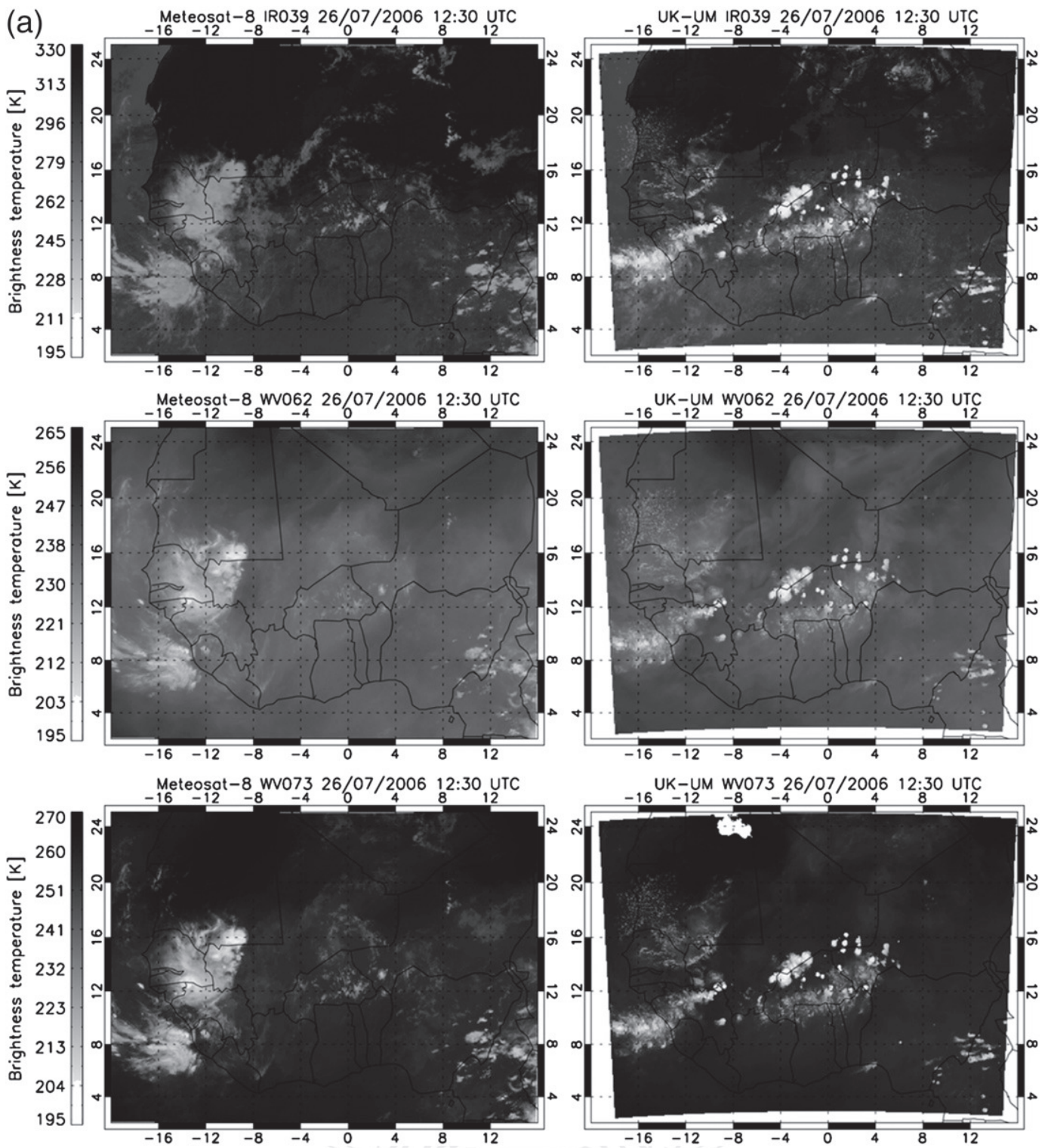

FIG. 1. (left) Real SEVIRI-MSG imagery and (right) simulated SEVIRI for (a) channels (top) 3.9, (middle) 6.2, and (bottom) $7.3 \mu \mathrm{m}$, (b) channels (top) 8.7 and (bottom) $10.8 \mu \mathrm{m}$, and (c) channels (top) 12 and (bottom) $13.4 \mu \mathrm{m}$ at 1230 UTC 26 Jul 2006.

\section{c. ForTraCC}

ForTraCC is a computer algorithm that allows tracking of the mesoscale convective system's (MCS's) radiative and morphological properties and forecasting of the evolution of these physical properties (based on cloud-top brightness temperature) up to $120 \mathrm{~min}$ ahead by using infrared satellite imagery $(10.8 \mu \mathrm{m})$. The main parts of this algorithm are as follows:

1) a cloud cluster detection method based on a size and temperature threshold
2) a statistical module to perform morphological and radiative parameters of each MCS

3) a tracking technique based on MCS-overlapping areas between successive images

4) a forecast module based on MCS evolution in previous time steps

Step 4 was not used in this study because we were only interested in the MCS's life cycle characteristics. The details can be found in Machado and Laurent (2004) and Vila et al. (2008). 
JOBNAME: JAM 00\#00 2014 PAGE: 5 SESS: 8 OUTPUT: Mon Dec 9 16:25:37 2013 Total No. of Pages: 13

(b)
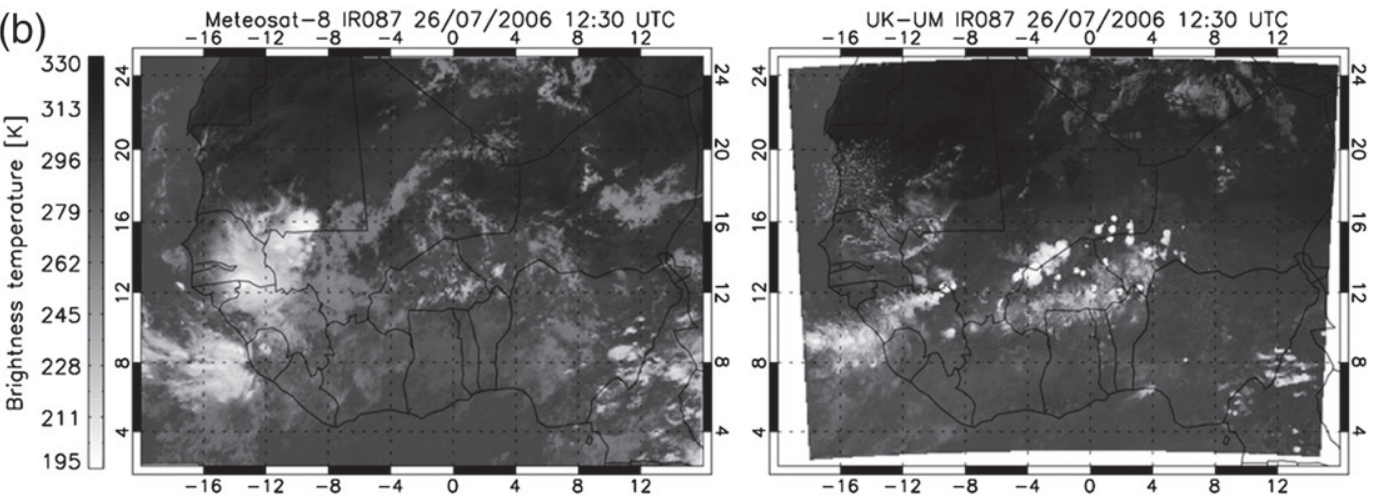

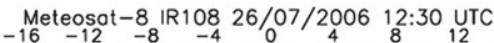
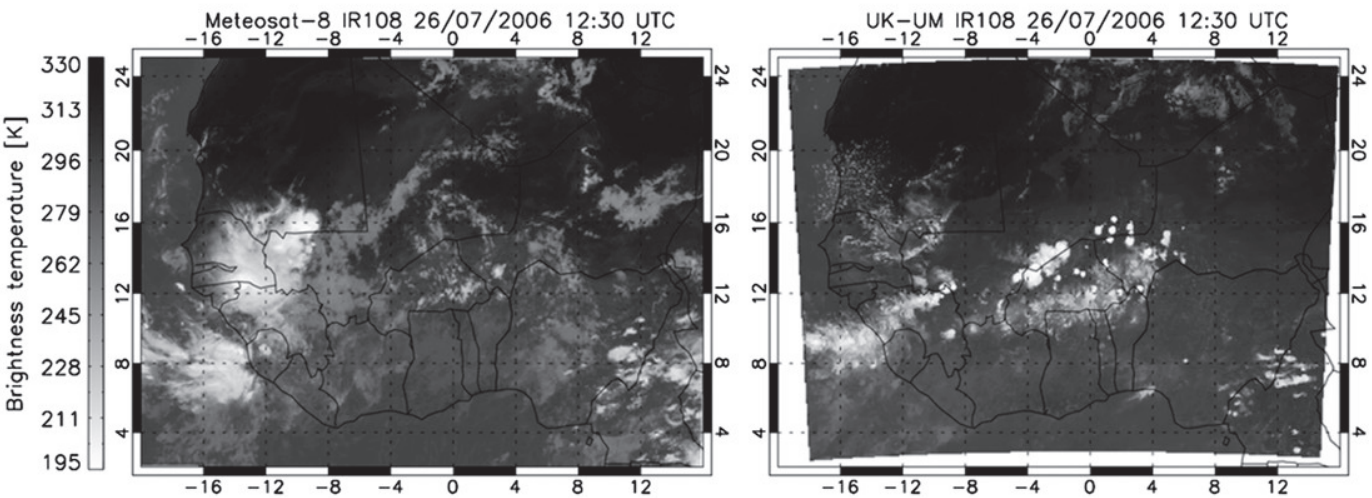

(c)
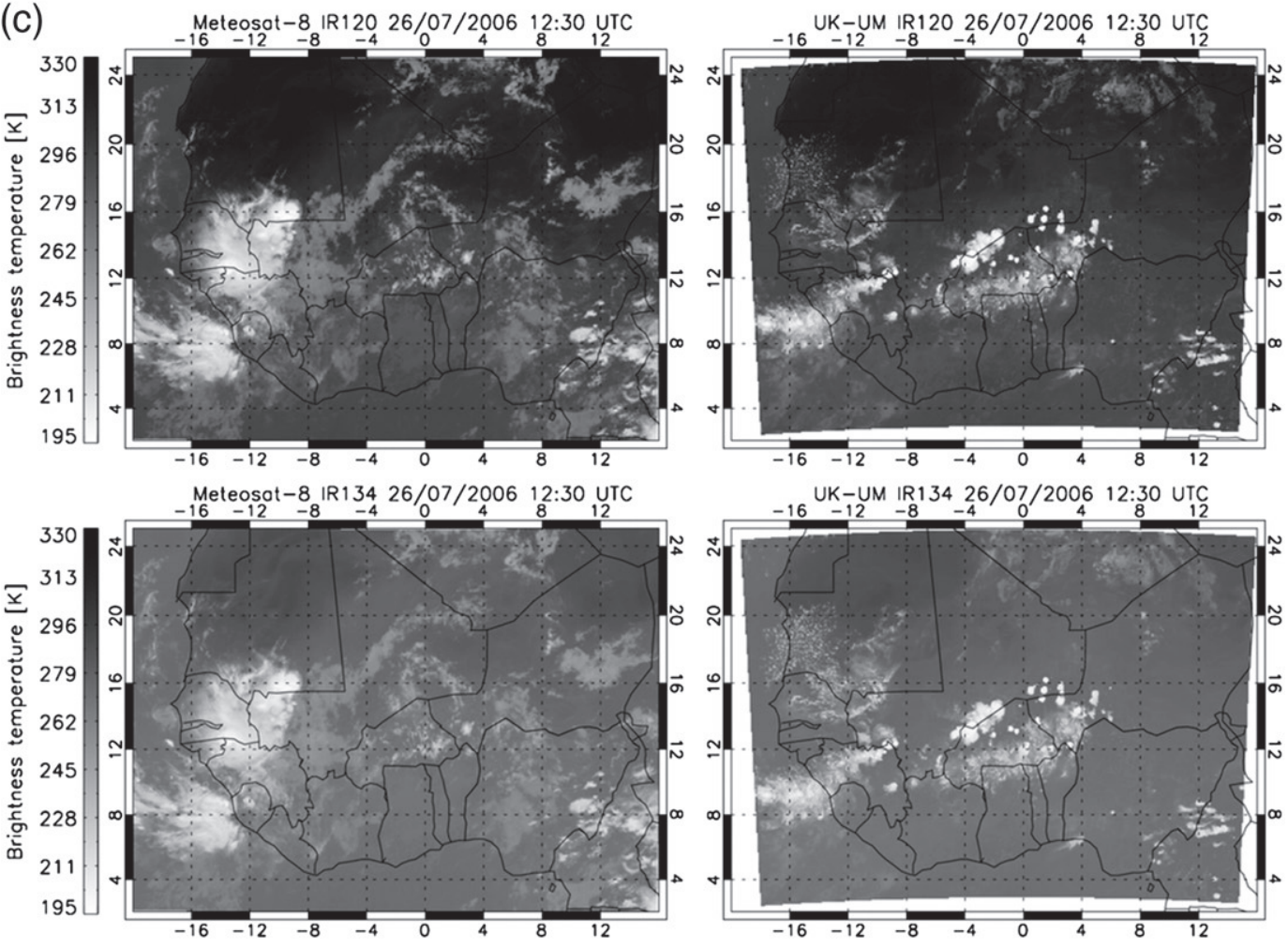

FIG. 1. (Continued) 


\section{Simulation analysis: Comparison between Cascade results and MSG-SEVIRI imagery}

With all SEVIRI-RTTOV model simulations, comparisons with the real SEVIRI measurements were done in three steps. First, the brightness temperature histograms for all simulated and real channels were assessed. After this, an EOF analysis was performed, followed by the analysis of the life cycle of the convective cells observed by satellite and simulated by UK UM. Below, the three analysis steps are discussed.

\section{a. Brightness temperature histograms}

As mentioned before, the $1.5-\mathrm{km}$ runs were initialized from an interpolation of the $12-\mathrm{km}$ runs and therefore, precise positioning of the convection cannot be expec-

F1 ted. Figures $1 \mathrm{a}-\mathrm{c}$ show an example of each SEVIRI channel, comparing the simulated and observed values. Visual inspection of the simulated and observed fields is generally encouraging, and the statistical analysis presented here will demonstrate that the statistics for the two fields are similar for several channels. Notice that the convection in the model and in reality are morphologically dissimilar; for example, UK UM fails to reproduce the mesoscale system observed near the western coast of Africa while producing many small convective cells over the center of the continent (Figs. 1a-c). The simulated 3.9- $\mu \mathrm{m}$ IR channel (Fig. 1a, top) shows brighter (colder) cloud tops, which is not represented accurately in the observations. The SEVIRI sensor has a technical limitation on this channel, where the measurements saturate for brightness temperatures colder than $260 \mathrm{~K}$. For the surface and lower and middle clouds, where the SEVIRI 3.9- $\mu \mathrm{m}$ IR channel does not saturate, the simulations are very similar to the real imagery. Simulations of the 6.2- $\mu \mathrm{m}$ water vapor $(\mathrm{WV})$ channel also show stronger brightness temperature gradients. A visual inspection indicates that all the other simulated channels seem to be very similar to the real measurements, despite the differences observed in the morphology of the clouds.

First, the brightness temperature distributions were assessed, calculating the normalized brightness temperature histograms for each channel. Figure 2 presents the brightness temperature histograms for each simulated channel (dashed gray line), combined with its real SEVIRI image (black line) at 1430 UTC 26 July 2006. In each histogram, the inset box shows in detail the left side of the entire histogram. Histograms from the 27 July 2006 case are very similar to those of the 26 July case and therefore, they will not be presented here.

As can be seen in Fig. 2, the brightness temperature distribution of the UK UM simulations and its associated real MSG observations are very similar for all window infrared channels.

The UK UM histograms are smoother because the spectral resolution of the RTTOV simulations is higher than the MSG-SEVIRI sensor's resolution. In the 3.9- $\mu \mathrm{m}$ SEVIRI histograms, the signal is noisier for brightness temperatures colder than $280 \mathrm{~K}$ due to the sensor's saturation in this specific band. Otherwise, the main differences in this channel are related to microphysical differences, that is, the concentration and size of ice and water droplets (Pilewskie and Twomey 1987; Ackerman et al. 1990; Strabala et al. 1994; Chylek and Borel 2004; Chylek et al. 2006). The frequency of the brightness temperature in the $273-260-\mathrm{K}$ region is a little higher in the simulation histograms for the first hours of the simulated period (not shown), indicating that convection starts earlier in the model.

The main feature found in the histograms is a difference in the distribution of high-level water vapor. By considering the 6.2 - and $7.3-\mu \mathrm{m}$ water vapor absorption channels, it is possible to see differences in the brightness temperature distributions both in the colder and in the warmer extremities. For the $6.2-\mu \mathrm{m}$ channel, the simulations' brightness temperature histogram has a peak around $242 \mathrm{~K}$, whereas the peak in the histogram of the real measurements is located near $238 \mathrm{~K}$. This difference is not clear in the 7.3- $\mu \mathrm{m}$ channel, but in this wavelength, the frequency of warmer values is higher. The differences are smaller at $7.3 \mu \mathrm{m}$, which has weaker water vapor sensitivity and therefore peaks lower in the atmosphere. The weighting function for the $6.2-\mu \mathrm{m}$ channel peaks at higher levels with its maximum being closer to the $400-300-\mathrm{hPa}$ layer, indicating that the larger difference found in this channel is related to the humidity distribution in UK UM at high levels. Furthermore, a small peak in the coldest brightness temperature region (inset histogram) is seen in all the simulated SEVIRI radiance histograms in Fig. 2. This peak is associated with the small spatial variance in the higher cloud tops in the simulated brightness temperature, which is not present in the measurements. The coldest cloud-top areas in UK UM are larger (in the horizontal area) and smoother compared with the real SEVIRI images. Figure 3 shows the real (left) and simulated (right) SEVIRI radiance $6.2-\mu \mathrm{m}$ channel from 1230 to 2030 UTC, where the areas of clear sky in the simulated water vapor images are, generally, warmer than in the observations (light orange zones). In the central portion of the images in Fig. 3, where the convection is very active in the simulations, the high levels to the north of the convective cells are much drier than in reality. The real situation (satellite image) has almost no convection in the central area, but it has significant 

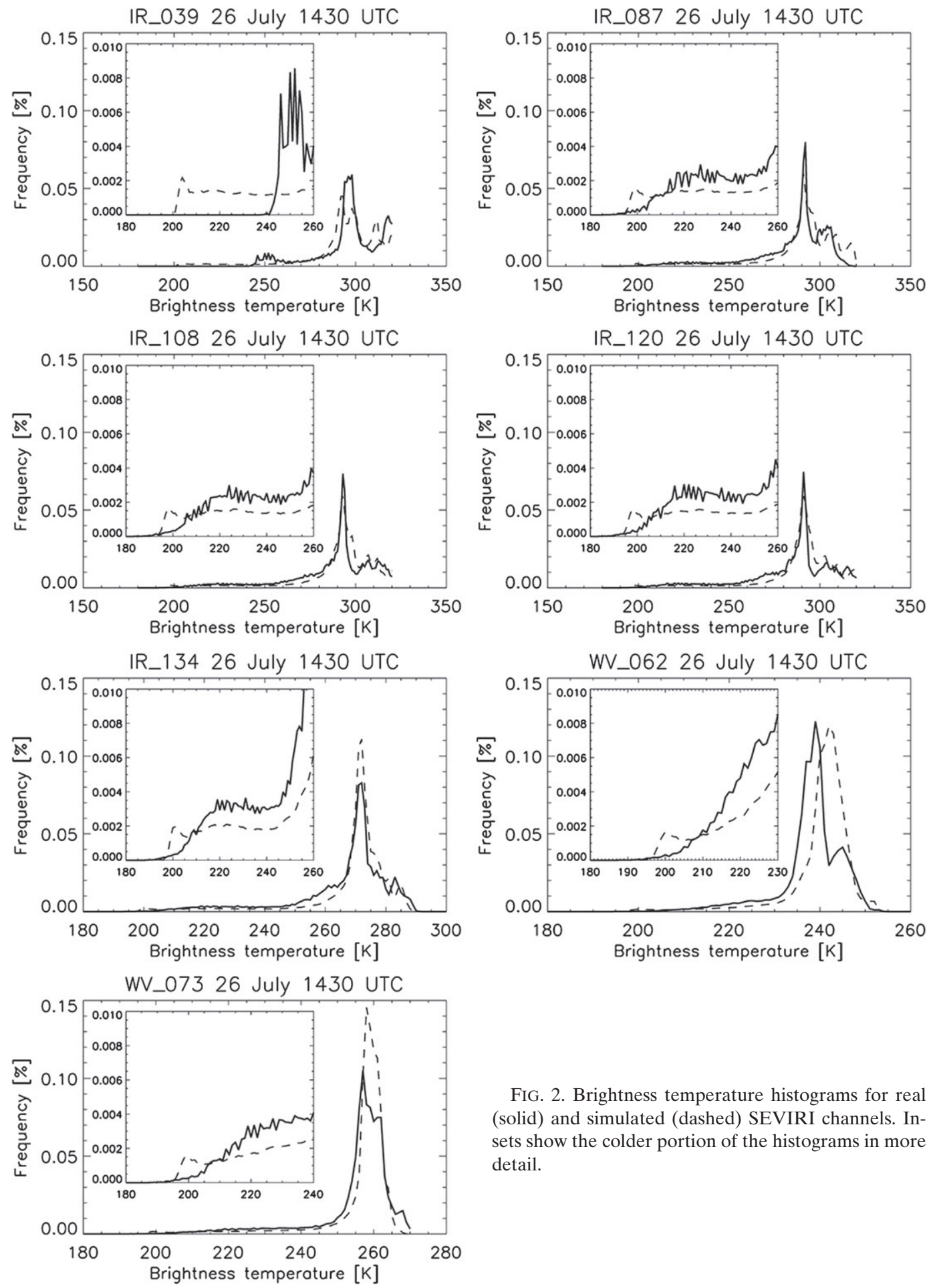

FIG. 2. Brightness temperature histograms for real (solid) and simulated (dashed) SEVIRI channels. Insets show the colder portion of the histograms in more detail.

convection in the southeastern corner with weaker highlevel humidity gradients between the clouds. For this same area, the simulations have similar convective activity with stronger humidity gradients than in reality (light orange zones). This indicates that the model is overestimating the downwelling fluxes near to the convective cells due to mass conservation, which makes the high levels drier than observed. 

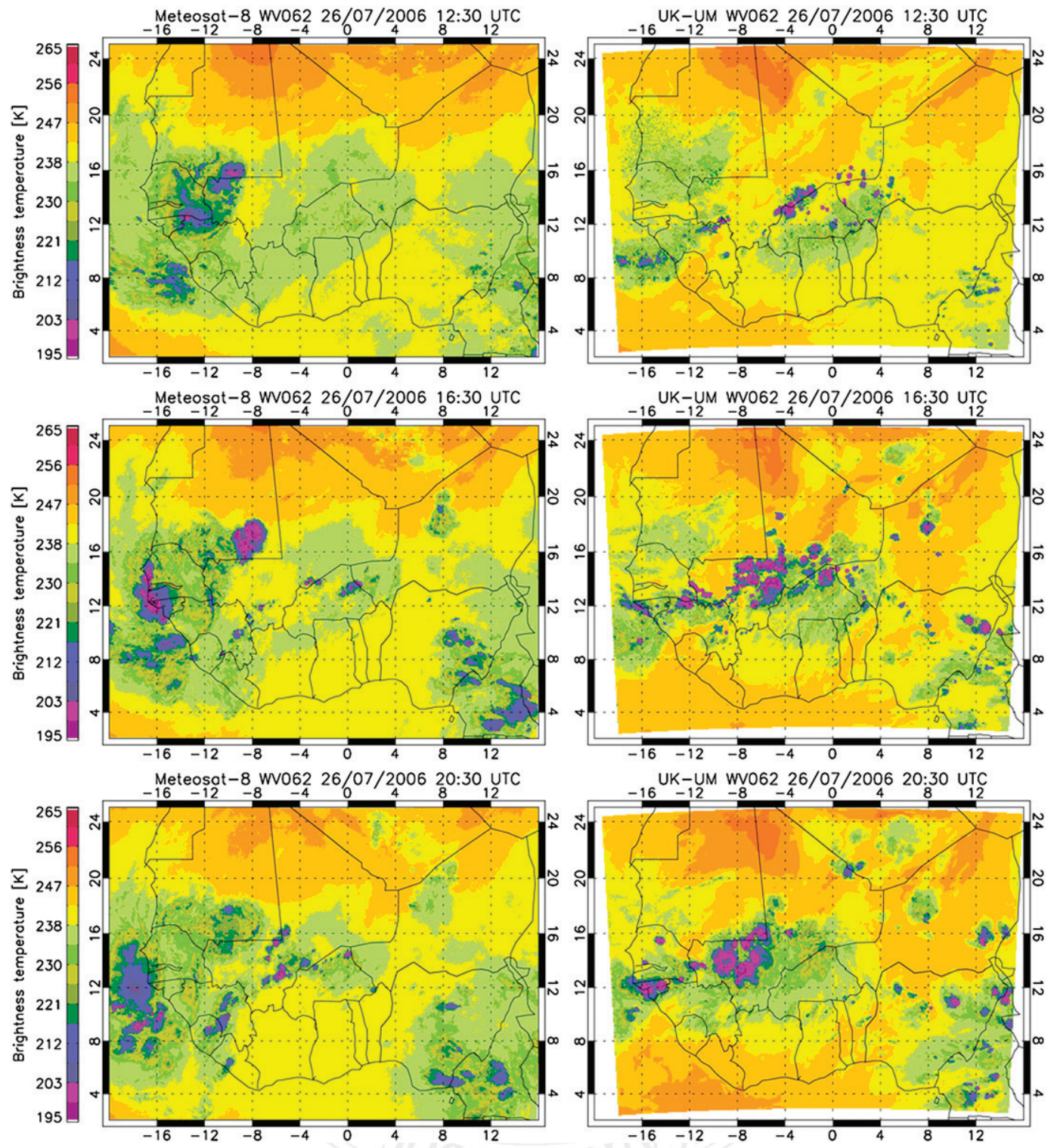

FIG. 3. (left) Real MSG measurements and (right) UK UM-RTTOV simulations at 1230, 1630, and 2030 UTC $26 \mathrm{Jul} 2006$. Notice that in the areas away from deep convection, brightness temperatures are generally warmer than in reality.

\section{b. Analysis using EOF}

The EOF analysis was applied to the observations and simulation for all the channels, except the ozone channel. The EOF was calculated separately for the 26 and 27 July 2006 cases, owing to the time discontinuity between the two periods. Figure 4 shows the first seven eigenvectors and eigenvalues calculated for each case using the entire image set for each day. The eigenvectors have seven dimensions (seven SEVIRI channels) and thus, to visualize these vectors, each one was plotted as a two-dimensional graph, where the vertical axis represents the dimension of each component (channel) and the horizontal axis represents its corresponding channel. The channels are ordered from the shorter (left) to the longer (right) wavelength.

It is possible to see that the first two eigenvectors are very similar for the observed SEVIRI images and for the UK UM-RTTOV simulations for both days. The third eigenvector also shows some similarity; it shows that the main variance is well described by UK UM. The first three eigenvectors explain, for both days, around $97 \%(62 \%, 22 \%$, and $13 \%$, respectively) of the variance of the real SEVIRI data. The simulated cases represent 

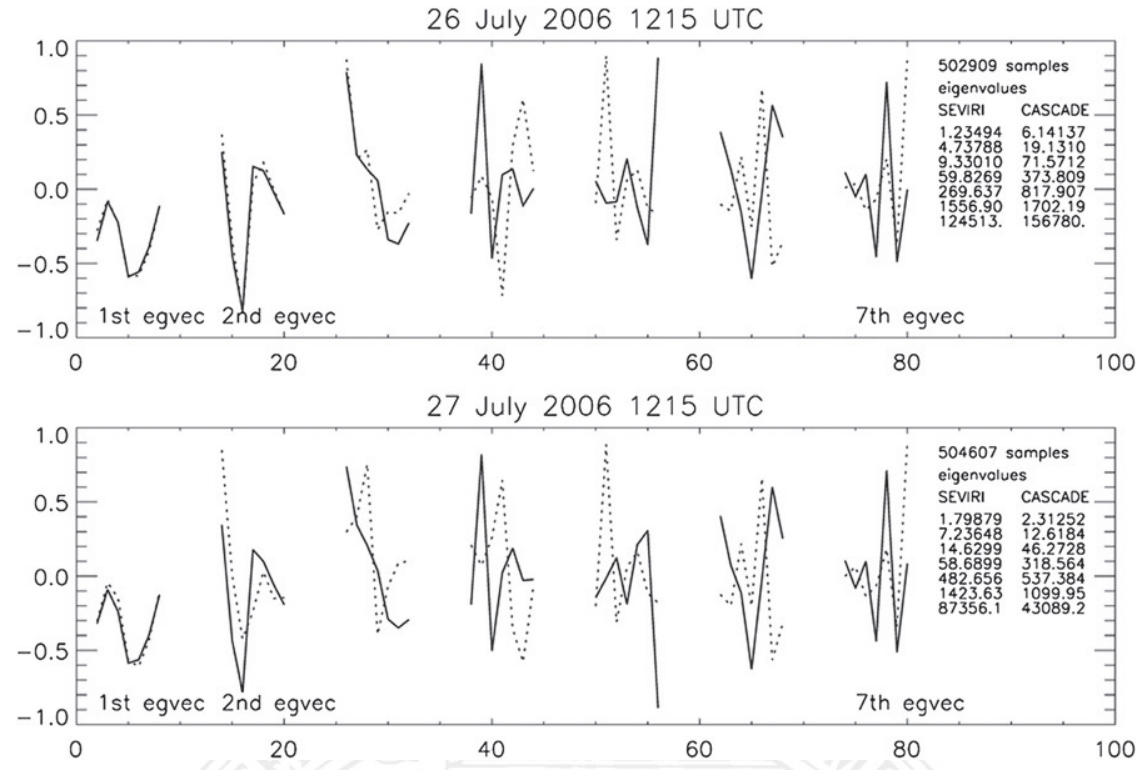

FIG. 4. EOF for entire period for (top) 26 and (bottom) 27 Jul. Solid lines represent SEVIRI and dashed lines represent UK UM-RTTOV simulations. Individual curves represent each of the seven eigenvectors (from first to seventh eigenvector). Tables on the right represent the associated seven eigenvalues from the first (top row) to the last (bottom row).

$97.5 \%$ on 26 July and $98.5 \%$ on 27 July. The higher-order eigenvectors explain less than $1 \%$ of the variance. The fourth eigenvector is nearly the same; however, it is out of phase, and the fifth and higher-order eigenvectors between the simulations and observations are very different.

This analysis indicates that the general aspects of the life cycle and organization of the convection is well represented by UK UM. The first eigenvector is related to the main variability of the brightness temperature in the satellite image, which is the diurnal cycle associated with solar heating. The results indicate that the model captures the main phase of the diurnal cycle. By comparing the satellite and simulated images, it is possible to discern a higher number of clouds in the simulations, which will be discussed in more detail in section $3 \mathrm{c}$ by examination of the temporal and spatial organization of the cloud. The second and third eigenvectors do not match as well as the first; however, they are also very similar and have the same phase, showing that UK UM is also reproducing well the properties of the secondand third-order variability.

To verify whether the eigenvectors change for different convective activity stages, the EOF was also calculated hourly in four samples (i.e., 1300, 1315, 1330, and 1345 UTC). This analysis showed that the results are consistent and reproducible for different times and dates.

\section{c. ForTraCC}

The ForTraCC algorithm was used to assess the life cycle of the mesoscale convective cloud organization, using the SEVIRI 10.8- $\mu \mathrm{m}$ channels simulated by UK UM-RTTOV and by the observed SEVIRI-MSG imagery. An MCS was defined as a cluster of pixels with a brightness temperature lower than $235 \mathrm{~K}$, as used by Machado and Rossow (1993). ForTraCC is capable of monitoring the evolution, from formation to dissipation, of convective clouds present in a geostationary satellite image sequence. The smallest size of cloud cluster tracked was as large as 75 pixels. By this definition, any single convective cell larger than this threshold will be considered an MCS. The tracking procedure can detect MCS formation from a merge situation with another MCS and/or by splitting. The definition of the minimal MCS size tracked is related to the pixel size and image time interval; this study uses 3-km spatial resolution (UK UM 1.5-km resolution was downscaled to $3 \mathrm{~km}$ for this analysis) and a 15-min time interval. For the smallest MCS moving at $15 \mathrm{~m} \mathrm{~s}^{-1}$, overlapping is possible only for cloud clusters larger than 75 pixels, corresponding to an effective radius of approximately $22 \mathrm{~km}$. Lean et al. (2008) used a similar approach to calculate the statistics of convective cells. However, their approach counted the number of cells and their sizes, which cannot follow the life cycle of each convective cell nor identify situations where a cell splits into two cells or where two or more cells merge into a larger cell. For our analysis, we only considered MCSs or single convective cells that exceeded the size threshold, referred to by Vila et al. (2008) as spontaneous generation. The ForTraCC output corresponds to a list 

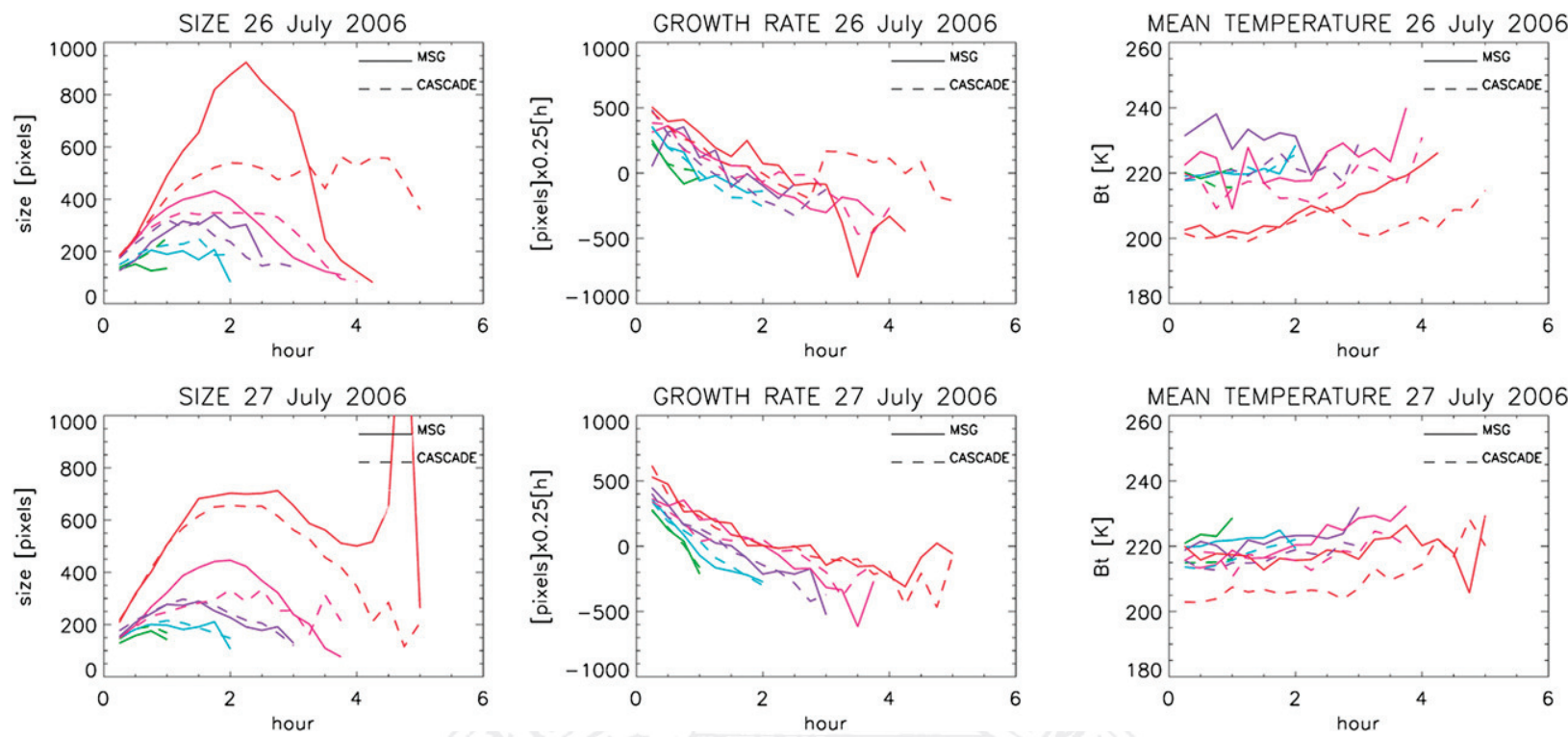

AU7 FIG. 5. (left) Mean size (top), (center) growth rate, and (right) mean temperature for the convective systems for (top) 26 and (bottom) 27 Jul 2006. Dashed lines represent UK UM-RTTOV simulation statistics, and green, light blue, purple, pink, and red are the systems living up to $1,2,3,4$, and $>4 \mathrm{~h}$, respectively.

of time steps for each MCS, describing the time evolution of several radiative and morphological properties and the merge or split situations.

For this analysis, the following parameters were analyzed as functions of the length of the life cycle: size (assuming that the MCS has a circular shape), mean brightness temperature, and growing rate, which is defined as $\Delta E=(1 / a)(d a / d t)$, where $a$ is the area covered by $T_{\text {ir }}<235 \mathrm{~K}$. The growing rate is defined by Machado and Laurent (2004) as the normalized area expansion related to the upper-level wind divergence, and it can be used as a proxy for the length of the life cycle and convective activity of the MCS.

Figure 5 shows the mean size, mean growth rate, and mean brightness temperature as functions of the length of the life cycle for all the observed and simulated MCSs. Systems initiated from merge or split situations are not accounted for in Fig. 5. For some situations, none or very few systems lived up to a certain defined class. For example, the 5-h class is not statistically significant; however, the ones that lived up to $4.5 \mathrm{~h}$ are. To address this statistical issue, the statistics related to the final hours of these few systems were discounted from our analysis, treating these systems as though they had a shorter life cycle, which explains why, sometimes, the solid lines (MSG) end earlier than the dashed lines (UK UM) in Fig. 5.

The sizes of systems with life cycles shorter than $4 \mathrm{~h}$ are similar. However, as the systems evolve longer life cycles, the model produces smaller systems. Laurent et al. (2002) show a nearly linear relationship between size and duration of life cycle. This longer life cycle should be related to the excess of higher levels of humidity where the convection occurs, as discussed in section 3a. As shown in Table 2 (the number of MCSs tracked for each lifetime class), the number of systems with life cycles longer than $5 \mathrm{~h}$ is very small when compared with shorter-lived systems. Table 2 also shows the large number of convective systems in the simulated cases. This difference in the number of convective systems appears in the class of MCSs lasting more than $1 \mathrm{~h}$.

TABLE 2. Convective systems' frequency for each lifetime class for the UK UM-RTTOV simulations and real SEVIRI-MSG imagery.

\begin{tabular}{lccrrr}
\hline \hline & \multicolumn{2}{c}{26 Jul } & & \multicolumn{2}{c}{27 Jul } \\
\cline { 2 - 3 } \cline { 5 - 6 } Lifetime $(\mathrm{h})$ & MSG & UK UM & & MSG & UK UM \\
\hline 0.5 & 29 & 39 & & 30 & 34 \\
0.75 & 24 & 31 & & 22 & 35 \\
1 & 13 & 26 & & 21 & 18 \\
1.25 & 9 & 23 & 7 & 21 \\
1.5 & 7 & 24 & & 13 & 22 \\
1.75 & 7 & 14 & & 18 \\
2 & 5 & 11 & & 17 \\
2.25 & 3 & 12 & & 15 \\
2.5 & 3 & 5 & & 10 & 14 \\
2.75 & 0 & 4 & 7 & 8 \\
3 & 3 & 8 & & 10 & 18 \\
4 & 2 & 5 & 4 & 5 \\
5 & 0 & 3 & 2 & 2 \\
\hline
\end{tabular}


TABLE 3. Number of MCSs tracked and amount selected for analysis for the 26 and $27 \mathrm{Jul} 2006$ cases.

\begin{tabular}{lccccc}
\hline \hline & \multicolumn{2}{c}{ 26 Jul } & & \multicolumn{2}{c}{ 27 Jul } \\
\cline { 2 - 3 } \cline { 5 - 6 } & MSG & UK UM & & MSG & UK UM \\
\hline No split or merge & 105 & 205 & & 145 & 227 \\
Split or merge & 122 & 371 & & 224 & 548 \\
Total & 227 & 576 & & 369 & 775 \\
\hline
\end{tabular}

Table 3 shows the number of MCSs tracked for each case, making clear that the convection in UK UM produced more cells than are observed, and the fraction of MCSs splitting and/or merging is around $10 \%$ higher for the simulations. However, as shown in Fig. 5, the MCSs in the model are generally smaller. Therefore, the analysis shows the tendency for the model to resolve the convection but to underestimate the maximum size and overestimate the number of convective cells for the two cases studied. For systems surviving at least $3 \mathrm{~h}$, the mean size is very similar for the simulations and real measurement sequences, despite the difference in the number of MCSs, showing that the life cycle of the resolved convection in UK UM is well reproduced for a system with a short lifetime.

For the 26 July case, we can see that the temporalspatial scale of the cloud organization is well described by the model for systems with life cycles of at least $4 \mathrm{~h}$. For systems that live beyond $4 \mathrm{~h}$, their size is again underestimated. The area expansion is related to the upper-level divergence, and it is a proxy of the mass flux inside the clouds (Machado and Laurent 2004). The model presents a very good description of the area expansion for nearly all systems, except for the larger ones at the end of the life cycle. This is probably associated with the trend of the area expansion increase that occurs at the end of the life cycle of the longer-lived MCSs on 26 July. For the 27 July case, the mean size and mean growth rate are very similar for the real and simulated SEVIRI radiances. The number of MCSs with a lifetime of more than $4 \mathrm{~h}$ is small due to their natural low frequency. If this study had a longer period of simulation, then the dynamics of these longer-living MCSs resolved by UK UM could be much better assessed.

Convective systems with life cycles of between 3 and $4 \mathrm{~h}$ are, on average, smaller in the model than observed by satellite. Clusters with lifetimes of between 4 and $5 \mathrm{~h}$ (pink lines) have very similar growth rates in the simulations and in the real SEVIRI measurements for the 27 July case (Fig. 3, bottom), but with greater differences for the 26 July case. The growth rate is very similar for all other lifetime classes. Looking at the clusters' mean brightness temperature, the major differences occur for the longer-lived systems. We see that for all system lifetime classes, the real convective cloud tops tend to be warmer than the simulated ones. For the systems with a lifetime of greater than $5 \mathrm{~h}$, the difference in the mean brightness temperature is largest, but we cannot state that this is a systematic error in the UK UM, owing to the few cases available here.

\section{Conclusions}

The methodology presented in this study was used to assess the morphological and radiative characteristics of the convection resolved by UK UM, and it can be applied to any other forecast or climate model. The main results are highlighted below.

1) Using histograms, it was verified that the simulated brightness temperature distribution in the infrared window channels $(3.9,8.7,10.8,12$, and $13.4 \mu \mathrm{m})$ match very well with their respective distributions observed by SEVIRI. The main differences between the simulations and the real observations were found in the 6.2- and 7.2- $\mu \mathrm{m}$ water vapor absorption bands. The right-side peaks of the 6.2- and 7.2- $\mu \mathrm{m}$ histograms (Fig. 2) are located at warmer values than their respective real SEVIRI ones, being more noticeable for the $6.2-\mu \mathrm{m}$-channel histogram. This shift to the warmer side of the histograms indicates an error in the high-level horizontal distribution of humidity by UK UM, where the horizontal drier areas of the UK UM high-level humidity are much larger than in the SEVIRI measurements (Fig. 3).

2) The EOF analysis was used as a tool to verify whether variability of convection is well reproduced by UK UM. The first three eigenvectors together represent around $98 \%$ of the variance of the simulated and real SEVIRI measurements, and they are similar (first and second are the most similar) and in phase. This result shows that the convection resolved by UK UM has all the main characteristics found in the real SEVIRI images, but it does not specify precisely which characteristics. Therefore, this statistical tool was used here only as a measure of similarity between the simulated- and the real-image datasets. The histogram and mainly the ForTraCC complement this result.

3) The approach of spatial-temporal cloud organization for determining the life cycles of the convective systems has been shown to be a useful tool for assessing the radiative and morphological characteristics of the convection resolved by UK UM. It has made it possible to compare the UK UM-RTTOVsimulated radiances with the real SEVIRI measurements, by examining their morphological and 
radiative characteristics instead of by pixel-based methods. The histogram analysis gives information about the brightness temperature distribution, and the EOF analysis shows that the main features of the cloud fields are reproduced by UK UM; however, only by using ForTraCC was it possible to identify the MCSs in both datasets and to look directly at the convection organization and the evolution of their life cycles. This tool makes it possible to account for the number of convective cells in each dataset, which reveals a tendency for the model to develop too many cells. Furthermore, it was possible to assess the characteristics of the life cycle for systems with different durations, showing that the model is capable of reproducing the observed convective life cycle very closely. However, the short period of the simulations precludes drawing any conclusions regarding the statistical study of convective systems with life cycles longer than $4 \mathrm{~h}$ when there are only a few cases. A longer time series could give more information for this specific group, and this is recommended for future studies.

Acknowledgments. The authors acknowledge the Coordenação de Aperfeiçoamento de Pessoal de Nível Superior (CAPES) for the doctoral scholarship, John Eyre for assistance with Renato Galante's visit to the Met Office (U.K.), Paul Field and the Cascade project group for the Unified Model support, and the Met Office (U.K.) satellite assimilation group for help with the study. This research was supported by FAPESP Grant 2009/15235-8.

\section{REFERENCES}

Ackerman, S. A., W. L. Smith, J. D. Spinhirne, and H. E. Revercomb, 1990: The 27-28 October 1986 FIRE IFO cirrus case study: Spectral properties of cirrus clouds in the $8-12 \mu \mathrm{m}$ window. Mon. Wea. Rev., 118, 2377-2388.

Barnaby, S. L., A. J. Matthews, and G. M. S. Lister, 2011: The diurnal cycle of precipitation over the Maritime Continent in a high-resolution atmospheric model. Quart. J. Roy. Meteor. Soc., 137, 934-947.

Chaboureau, J. P., J. P. Cammas, P. Mascart, J. P. Pinty, C. Claud, R. Roca, and J. J. Morcrete, 2000: Evaluation of a cloud system life-cycle simulated by the Meso-NH model during FASTEX using METEOSAT radiances and TOVS-3I cloud retrievals. Quart. J. Roy. Meteor. Soc., 126, 1735-1750.

Chevallier, F., and G. Kelly, 2002: Model clouds as seen from space: Comparison with Geostationary imagery in the $11-\mu \mathrm{m}$ window channel. Mon. Wea. Rev., 130, 712-722.

Chylek, P., and C. Borel, 2004: Mixed phase cloud water/ice structure from high spatial resolution satellite data. Geophys. Res. Lett., 31, L14104, doi:10.1029/2004GL020428.

- S. Robinson, M. K. Dubey, M. D. King, Q. Fu, and W. B. Clodius, 2006: Comparison of near-infrared and thermal infrared cloud phase detections. J. Geophys. Res., 111, D20203, doi:10.1029/2006JD007140.

Davies, T., M. J. P. Cullen, A. J. Malcom, M. H. Mawson, A. Staniforth, A. A. White, and N. Wood, 2005: A new dynamical core for the Met Office's global and regional modelling of the atmosphere. Quart. J. Roy. Meteor. Soc., 131, 1759-1782.

Done, J., C. A. Davis, and M. Weisman, 2004: The next generation of NWP: Explicit forecasts of convection using the Weather Research and Forecasting (WRF) model. Atmos. Sci. Lett., 5, 110-117.

Eyre, J. R., 1991: A fast radiative transfer model for satellite sounding systems. ECMWF Research Dept. Tech. Memo. 176, 28 pp.

Joly, A., and Coauthors, 1997: The fronts and Atlantic Storm Track Experiment (FASTEX): Scientific objectives and experimental design. Bull. Amer. Meteor. Soc., 78, 1917-1940.

Laurent, H., L. T. A. Machado, C. A. Morales, and L. Durieux, 2002: Characteristics of the Amazonian mesoscale convective systems observed from satellite and radar during the WETAMC/LBA experiment. J. Geophys. Res., 107, 8054, doi:10.1029/2001JD000337.

Lean, H. W., P. A. Clark, M. Dixon, N. M. Roberts, A. Fitch, R. Forbes, and C. Halliwell, 2008: Characteristics of highresolution versions of the Met Office Unified Model for forecasting convection over the United Kingdom. Mon. Wea. Rev., 136, 3408-3434.

Locke, A. P., A. R. Brown, M. R. Bush, G. M. Martin, and R. N. B. Smith, 2000: A new boundary-layer mixing scheme. Part I: Scheme description and single-column model tests. Mon. Wea. Rev., 128, 3187-3199.

Machado, L. A. T., and W. B. Rossow, 1993: Structural characteristics and radiative properties of tropical cloud clusters. Mon. Wea. Rev., 121, 3234-3260.

- and H. Laurent, 2004: The convective system area expansion over Amazonia and its relationships with convective system life duration and high-level wind divergence. Mon. Wea. Rev., 132, 714-725.

Natural Environment Research Council, cited 2013: Cascade-scale interactions in the tropical atmosphere data. NCAS British Atmospheric Data Centre, 2008-2011. [Available from http://badc.nerc.ac.uk/view/badc.nerc.ac.uk_ATOM_dataent_ 12175812387925961.]

Pearson, K. J., R. J. Hogan, R. P. Allan, G. M. S. Lister, and C. E. Holloway, 2010: Evaluation of the model representation of the evolution of convective systems using satellite observations of outgoing longwave radiation. J. Geophys. Res., 115, D20206, doi:10.1029/2010JD014265.

Pilewskie, P., and S. Twomey, 1987: Discrimination of ice from water in clouds by optical remote sensing. Atmos. Res., 21, 113-122.

Ploshay, J. J., and N. C. Lau, 2010: Simulation of the diurnal cycle in the tropical rainfall and circulation during boreal summer with a high-resolution GCM. Mon. Wea. Rev., 138, 3434-3453.

Ringer, M. A., J. M. Edwards, and A. Slingo, 2003: Simulation of satellite channel radiances in the Met Office Unified model. Quart. J. Roy. Meteor. Soc., 129, 1169-1190.

Romero, R., C. A. Doswell, and R. Riosalido, 2001: Observations and fine-grid simulations of a convective outbreak in northeastern Spain: Importance of diurnal forcing and convective cold pools. Mon. Wea. Rev., 129, 2157-2182.

Sato, T., H. Miura, M. Satoh, Y. N. Takayabu, and Y. Wang, 2009: Diurnal cycle of precipitation in the tropics simulated in a global cloud-resolving model. J. Climate, 22, 4809-4826.

Saunders, R. W., M. Matricardi, and P. Brunel, 1999: An improved fast radiative transfer model for assimilation of 
satellite radiance observations. Quart. J. Roy. Meteor. Soc., 125, 1407-1426.

Schmetz, J., P. Pili, S. Tjemkes, D. Just, J. Kerkmann, S. Rota, and A. Ratier, 2002: An introduction to Meteosat Second Generation (MSG). Bull. Amer. Meteor. Soc., 83, 977-992.

Slingo, A., K. L. Hodges, and G. J. Robinson, 2004: Simulation of the diurnal cycle in a climate model and its evaluation using data from Meteosat 7. Quart. J. Roy. Meteor. Soc., 130, 1449-1467.

Speer, M. S., and L. M. Leslie, 2002: The prediction of two cases of severe convection: Implications for forecast guidance. Meteor. Atmos. Phys., 80, 165-175.
Strabala, K. I., S. A. Ackerman, and W. P. Menzel, 1994: Cloud properties inferred from $8-12-\mu \mathrm{m}$ data. J. Appl. Meteor., 33, 212-229.

Vila, D., L. A. T. Machado, H. Laurent, and I. Velasco, 2008: Forecast and Tracking the Evolution of Cloud Clusters (ForTraCC) using satellite infrared imagery: Methodology and validation. Wea. Forecasting, 23, 233-245.

Wilson, D. R., and S. P. Ballard, 1999: A microphysically based precipitation scheme for the UK Meteorological Office Unified Model. Quart. J. Roy. Meteor. Soc., 125, 16071636. 